\title{
The application of 3D printed surgical guides in resection and reconstruction of malignant bone tumor
}

\author{
FENGPING WANG ${ }^{1}$, JUN ZHU $^{2}$, XUEJUN PENG ${ }^{3}$ and JING SU ${ }^{4}$ \\ ${ }^{1}$ Department of Ultrasound, Linyi People's Hospital, Linyi, Shandong 276000; ${ }^{2}$ Department of Orthopaedics, \\ Yidu Central Hospital of Weifang, Weifang, Shandong 262500; ${ }^{3}$ Department of Traumatology, Linyi People's Hospital, \\ Linyi, Shandong $276000 ;{ }^{4}$ Community Health Center of Yinque Mountain, Linyi, Shandong 276003, P.R. China
}

Received March 14, 2017; Accepted June 27, 2017

DOI: $10.3892 / \mathrm{ol} .2017 .6749$

\begin{abstract}
The clinical value of 3D printed surgical guides in resection and reconstruction of malignant bone tumor around the knee joint were studied. For this purpose, a sample of 66 patients from October 2013 to October 2015 were randomly selected and further divided into control group and observation group, each group consisted of 33 cases. The control group was treated by conventional tumor resection whereas, in the observation group, the tumor was resected with 3D printed surgical guide. However, reconstruction of tumor-type hinge prosthesis was performed in both groups and then the clinical effect was compared. Results show that there was no significant difference in the operation time between the two groups ( $p>0.05)$. However, the blood loss, resection length and complication rate were found significantly lower in the observation group than in the control group $(\mathrm{p}<0.05)$. The rate of negative margin and the recurrence rate in the 12-month follow-up ( $p>0.05$ ) between two groups were statistically the same ( $>0.05)$, whereas the Musculoskeletal Tumor Society (MSTS) score of the knee joint in the observation group was significantly better than that of the control group $(p<0.05)$ after 1, 3, 6 and 12 months of the operation. Consequently, the $3 \mathrm{D}$ printed surgical guides can significantly improve the postoperative joint function after resection and reconstruction of malignant bone tumor around the knee joint and can reduce the incidence of complications.
\end{abstract}

\section{Introduction}

A majority of primary malignant bone tumors occur in and around the knee joint (1). Several studies $(2,3)$ have pointed out that the patients of limb salvage surgery had the same long-term survival rate as the patients of amputation surgery;

Correspondence to: Dr Xuejun Peng, Department of Traumatology, Linyi People's Hospital, 27 East Jiefang Road, Linyi, Shandong 276000, P.R. China

E-mail: pmn7w4@163.com

Key words: 3D printing, knee bone tumor, prosthetic reconstruction however, they had significantly improved quality of life and less complications. The tumor patients being young require almost perfection in limb salvage surgery because of their long-term usage of the post-operation joint function. Accurate and complete resection and reconstruction of joint function are the key factors to determine the effect of the surgery. Surgical guide combined with computer computed tomography (CT) three-dimensional reconstruction technology with 3D print can significantly improve the accuracy of osteotomy, reduce the rate of surgical complications and improve the stability of joint reconstruction $(4,5)$. At present, 3D printing technology is used in the roduction of orthopedic experimental model, surgical auxiliary material printing and the printing of implant and joint surgery (6). For example, the 3D acetabular model produced by Won et al (7) was used in the total hip arthroplasty surgery for severe hip deformity patients and images confirmed that the prosthesis components were accurately implanted. The aim of this study was to evaluate the value of $3 \mathrm{D}$ printed surgical guides in resection and reconstruction of malignant bone tumors around the knee.

\section{Patients and methods}

Patient characteristics. From October 2013 to October 2015, 66 patients with malignant knee tumor confirmed by pathology were included in our study. The patients were included based on: i) Primary malignant tumors of the knee, surgical excision and limb salvage where 3D printing was completed; ii) unilateral lesions, no distant metastasis, survival was expected to be $<12$ months and iii) treatment compliance, complete clinical data, access to informed consent. Exclusion criteria were: i) Patients with combined with malignant tumor at other parts, knee disease such as osteoarthritis, rheumatoid disease and knee deformity; ii) severe osteoporosis or recent use of steroids; iii) patients combined with underlying diseases such as heart, liver, lung, kidney, brain and other organ dysfunction, and autoimmune diseases. The patients were divided, according to the order of admission, into the control group and the observation group at random where each group consisted 33 cases. The control group included 20 males and 13 females aged $22-58$ years $(42.5 \pm 13.6$ years). From these, 18 cases had left lesions, and 15 cases the right. Furthermore, out of 33 cases, the tumor was located in the distal femur in 
16 cases and in 17 cases it was in proximal tibia. Regarding pathology type, 13 cases were osteosarcoma, chondrosarcoma in 11 cases and 9 cases were giant cell tumor of the bone. Based on Enneking tumor staging, 15 cases were found in stage I and 18 cases were in stage II. Finally, tumor diameter was $2.5-13.6 \mathrm{~cm}$ with average $6.7 \pm 3.5 \mathrm{~cm}$. The observation group consisted of 18 males and 15 females aged 26-62 years (with $44.7 \pm 15.5$ mean). Here, the left lesion was found in 16 cases and the right lesion in 17 cases. Moreover, the tumor was located in distal femur in 13 cases and in proximal tibia in 20 cases. There were 15 cases of osteosarcoma, 10 cases of chondrosarcoma and 8 cases of giant cell tumor of the bone. Regarding Enneking tumor staging, 17 cases were in stage I and 16 cases were in stage II. The tumor diameter range was $3.0-12.5 \mathrm{~cm}$ with mean diameter $6.6 \pm 3.2 \mathrm{~cm}$. Baseline data in the two groups were comparable. This study was approved by the Ethics Committee of Linyi People's Hospital. Signed written informed consents were obtained from the patients and/or guardians.

Research methods. All the procedures were completed with the help of same operating and nursing team. For the control group, the conventional tumor reaction method was used whereas 3D printed surgical guide for the resection of the tumor was used on observation group. Furthermore, both groups were performed with custom tumor hinge knee prosthesis reconstruction.

Preoperative preparation. In order to establish the 3D tumor model, the GE 64-slice spiral CT scanner (GE Medical Systems, Waukesha, WI, USA) was adopted with scanning from the pelvis to the foot where the slice thickness was $0.625 \mathrm{~mm}$. The original image data were imported into Mimics 10.01 software (Materialise, Leuven, Belgium) in DICOM format. In order to build the 3D skeletal model, threshold selection and region growing function were used. The images were saved in STL format. Then Imageware 13.2 software (Media Cybernetics, Silver Springs, MD, USA) was used for the model matching and thus length, distal femur, proximal tibia, the diameter of the medullary cavity and other anatomic parameters were measured. CT scanning was performed on the allogeneic bone grafts (Orion Biomaterials Co., Ltd., Shaanxi, China), for repairing large bone defects. By the same method, the 3D model was also established in this case.

Tumor resection. The Imageware 13.2 was used to accurately match the two lower limb skeletal models with tumor models, determining the tumor extent, designing the surgical excisional border and designing the osteotomy position and angle according to the specific anatomic parameters of the lower limbs.

Simulated surgical resection and functional reconstruction. For this purpose, the Imageware 13.2 was again used to simulate the tumor resection process. The $3 \mathrm{D}$ model of allograft and the bone defect were trimmed and matched according to the contralateral side. As the tumor resection criteria should exceed the lesion by $3-5 \mathrm{~cm}$, while the repair of large bone defect reaching an exact match keeping lower limb line of force and length consistent.

$3 D$ printed surgical guide. The tumor removal navigation template and allograft trim template were initially saved
Table I. Comparison between groups on operative time, blood loss and resection length.

\begin{tabular}{lccc}
\hline Groups & $\begin{array}{c}\text { Operation } \\
\text { time }(\mathrm{min})\end{array}$ & $\begin{array}{c}\text { Blood } \\
\text { loss }(\mathrm{ml})\end{array}$ & $\begin{array}{c}\text { Resection } \\
\text { length }(\mathrm{cm})\end{array}$ \\
\hline Control & $135.6 \pm 32.7$ & $689.3 \pm 123.4$ & $13.5 \pm 4.8$ \\
Observation & $144.8 \pm 45.2$ & $647.8 \pm 137.8$ & $12.6 \pm 4.4$ \\
t & 0.456 & 4.529 & 4.659 \\
P-value & 0.685 & 0.037 & 0.034 \\
\hline
\end{tabular}

in IGES format and imported into UG NX 7.0 software (Electronic Data Systems Corp., Plano, TX, USA), 'stitched' into entity, the main bone tissue and tumor resection area were marked, $3.0 \mathrm{~mm}$ diameter cylindrical guide hole was designed and the 3D model of the final navigation template was processed and saved as an STL file, which was transferred to a 3D printing tool. The navigation template entity was created using photosensitive resin as the raw material.

Surgical procedures. In the control group, with continuous epidural anesthesia, extensive radical resection according to preoperative X-ray, CT and magnetic resonance imaging (MRI) data were obtained. The range of osteotomy was $5 \mathrm{~cm}$ outside the edge of the tumor measured by a steel rule and the range of soft tissue resection was $2-5 \mathrm{~cm}$ outside the MRI signal change. After the tumor resection, the stump was reamed, the wound and the bone marrow cavity was washed repeatedly by pulse, then immersed in distilled water for $30 \mathrm{~min}$. In order to deal with the type of femoral tumor, tumortype hinge prosthesis of the tibial plateau was first installed (Beijing Lidakang Technology Co., Ltd., Beijing, China), the stump was then reamed with bone cement, the intramedullary fixation rods and allograft bone prostheses were installed, and the normal force was maintained until the cement was solidified. However, for the type of proximal tibial tumor, the femoral surface prosthesis was first installed, the complex was then installed, the normal force was maintained until the cement was solidified. Finally, the patellar ligament insertion was sutured to the allograft bone by steel wires for the reconstruction of the knee device. In the case of observation group, the tumor resection navigation template was clung to the bone surface and fixed by Kirschner wire. The tumor was removed completely along the border of the navigation template with the pendulum saw.

Allograft bone was pruned under the guidance of allograft bone pruning navigation template and then combined with the knee prosthesis. To form allogeneic bone-prosthesis complex, two allogeneic tendons (Shanxi Aorui Biomaterials Co., Ltd.) were fixed by anchors at one end to the inner and outer collateral ligament attachment point, respectively. The rest of the operation was consistent with the control group.

Wearing a knee brace 3-6 months to protect the collateral ligament and early stage functional exercise was recommended as postoperative management.

Observation indicators. For observation indicators, the operative time, blood loss, resection length, negative margin 
Table II. Negative margin rate, the incidence of complications and recurrence rate (case, \%).

\begin{tabular}{lccccccccc}
\hline Groups & $\begin{array}{c}\text { Case } \\
\text { no. }\end{array}$ & $\begin{array}{c}\text { Negative } \\
\text { margin } \\
\text { rate }\end{array}$ & $\begin{array}{c}\text { Immune } \\
\text { rejection }\end{array}$ & Infection & $\begin{array}{c}\text { Delayed } \\
\text { healing }\end{array}$ & $\begin{array}{c}\text { Prosthesis } \\
\text { loosening, } \\
\text { fracture }\end{array}$ & $\begin{array}{c}\text { Bone fracture, } \\
\text { nerve and } \\
\text { vascular injury }\end{array}$ & $\begin{array}{c}\text { Incidence of } \\
\text { complication }\end{array}$ & $\begin{array}{c}\text { Recurrence } \\
\text { rate }\end{array}$ \\
\hline Control & 33 & $31(93.9)$ & 1 & 2 & 3 & 3 & 2 & $11(33.3)$ & $5(15.2)$ \\
Observation & 33 & $30(90.9)$ & 1 & 0 & 1 & 1 & 1 & $4(12.1)$ & $3(9.1)$ \\
$\chi^{2}$ & & - & & & & & & 4.227 & - \\
P-value & & 1.000 & & & & & & 0.040 & 0.708 \\
\hline
\end{tabular}

and complication rate were compared between the two groups. The recurrence rate of the patients was compared within a follow-up period of 12 months. The Soft Tissue Oncology Association (MSTS, Musculoskeletal Tumor Society) functional score was recorded after 1, 3, 6 and 12 months of the operation. MSTS system 6 indicators were included that ispain, limb function, satisfaction, brace assist, walking and gait, for which the points of 24-30 was considered as excellent, 18-23 was considered as good, 12-17 was medium and under 12 was considered as poor.

Statistical analysis. In order to perform statistical analysis, SPSS 20.0 (SPSS, Inc., Chicago, IL, USA) software was used for data entry and processing. Normality and homogeneity test on continuous data were performed. Furthermore, continuous scale data were expressed as mean \pm standard deviation (SD), and then further independent samples t-test was applied for comparisons between groups. Moreover, MSTS score at different time-points in the groups were compared using repeated measurement data analysis of variance. The non-continuous data were expressed by percentage (\%), and then the comparison was made between groups using $\chi^{2}$ test or Fisher exact probability. $\mathrm{P}<0.05$ was considered to indicate a statistically significant difference.

\section{Results}

The operation time, blood loss and resection length. The results depict (Table I), that there was no significant difference between the two groups in the operation time $(\mathrm{p}>0.05)$. However, the amount of blood loss and the resection length were significantly smaller in the observation group than in the control group $(\mathrm{p}<0.05)$.

Negative margin rate, the incidence of complications and recurrence rate. Table II shows that there was no significant difference in the negative rate and the recurrence rate between the two groups $(p>0.05)$. On the other hand, the incidence of complication in the observation group was found significantly lower than that in the control group $(\mathrm{p}<0.05)$.

Comparison of MSTS scores between groups. By comparing MSTS scores, it is found (Table III), that the MSTS scores of the knee joint in the observation group was significantly higher than that of the control group, respectively, after 1, 3,6 and 12 months of the operation $\left(\mathrm{F}_{\text {time }}=6.532, \mathrm{P}=0.003\right.$; $\left.\mathrm{F}_{\text {group }}=5.528, \mathrm{P}=0.019 ; \mathrm{F}_{\text {between }}=0.523, \mathrm{P}=0.489\right)$.
Table III. Comparison of MSTS scores between groups.

\begin{tabular}{lcccc}
\hline Groups & 1 month & 3 months & 6 months & 12 months \\
\hline Control & $14.5 \pm 3.3$ & $20.2 \pm 4.5$ & $24.8 \pm 6.2$ & $26.2 \pm 5.9$ \\
Observation & $16.6 \pm 3.8$ & $25.5 \pm 4.7$ & $27.2 \pm 6.6$ & $28.3 \pm 6.2$ \\
\hline
\end{tabular}

\section{Discussion}

Currently, tumor wide resection combined with rotating hinge prosthesis is the most applicable treatment of malignant bone tumors around the knee world-wide (8). Resection of the tumor often leads to loss of a large area of soft tissue, which is one of the most important causes for postoperative instability and dislocation (9). By using computer 3D reconstruction and measurement, we can accurately delineate the surgical boundary, save as much as possible on the soft tissue and bone tissue in the premise of complete resection of the tumor, provide a guarantee for postoperative joint reconstruction and functional recovery (10). At the same time, there are also studies (11), pointing out that the use of large allograft bone in the repair of bone defects and the establishment of $3 \mathrm{D}$ navigation template contour model can improve matching satisfaction, achieve the largest biological structure similarity for the knee surface replacement, and significantly increase range of motion of the knee after the operation. According to results of this study, there was no significant difference found in the operation time between the two groups, suggesting that preoperative $3 \mathrm{D}$ printing of the surgical guide plate did not extend the operation time, however, the results of different studies may vary (12). In fact, the blood loss, the resection the length and the complication rate were significantly lower in the observation group than in the control group, suggesting that 3D printed surgical guide can reduce surgical trauma. There was no significant difference in the negative rate and the tumor recurrence rate between the two groups, suggesting that the two methods share equivalent short-term and long-term effect in the surgical resection of lesions (13). In addition, in the observation group, the MSTS score of the knee joint was significantly better than that of the control group after, respectively, 1, 3, 6 and 12 months of operation, suggesting that 3D printing can greatly improve the function of joint and reduce the complication of operation after resection and reconstruction of malignant bone tumor around the knee joint, which is of important application value. 
Studies have shown that the main complications of limb salvage surgery are infection, prosthesis fracture, dislocation, aseptic loosening, peripheral fractures, nerve and vascular injury and delayed union of bone $(14,15)$, and these are often the leading cause of surgical failure. It is shown (16) that periprosthetic infection and aseptic loosening are the most common causes of prosthetic failure and revision. The use of $3 \mathrm{D}$ printing for surgical guide plate not only improves the accuracy of surgical resection by avoiding large segmental bone defects, but also improves the stability of knee joint after reconstruction and the matching degree and implantation accuracy of prosthesis together with large allograft bone in reconstruction of bone structure and soft tissue balance improves the mechanical strength and stability of the prosthesis.

However, the shortcomings of this study are the small sample sizes, the short follow-up time, and the many other factors that have influenced the surgical effect such as surgeon experience, patient conditions and postoperative functional exercise; therefore it requires further studies and validation.

\section{References}

1. Maki RG, Moraco N, Antonescu CR, Hameed M, Pinkhasik A, Singer S and Brennan MF: Toward better soft tissue sarcoma staging: Building on American Joint Committee on Cancer Staging Systems versions 6 and 7. Ann Surg Oncol 20:3377-3383, 2013.

2. Xu S, Yu X, Xu M, Fu Z, Chen Y, Sun Y and Su Q: Limb function and quality of life after various reconstruction methods according to tumor location following resection of osteosarcoma in distal femur. BMC Musculoskelet Disord 15: 453, 2014.

3. Robert RS, Ottaviani G, Huh WW, Palla S and Jaffe N: Psychosocial and functional outcomes in long-term survivors of osteosarcoma: A comparison of limb-salvage surgery and amputation. Pediatr Blood Cancer 54: 990-999, 2010.

4. Schweizer A, Fürnstahl P and Nagy L: Three-dimensional correction of distal radius intra-articular malunions using patient-specific drill guides. J Hand Surg Am 38: 2339-2347, 2013.
5. Inzana JA, Olvera D, Fuller SM, Kelly JP, Graeve OA, Schwarz EM, Kates SL and Awad HA: 3D Printing of composite calcium phosphate and collagen scaffolds for bone regeneration. Biomaterials 35: 4026-4034, 2014

6. Ma L, Zhou Y, Zhu Y, Lin Z, Wang Y, Zhang Y, Xia H and Mao C: 3D-printed guiding templates for improved osteosarcoma resection. Sci Rep 6: 23335, 2016.

7. Won SH, Lee YK, Ha YC, Suh YS and Koo KH: Improving pre-operative planning for complex total hip replacement with a Rapid Prototype model enabling surgical simulation. Bone Joint J 95: 1458-1463, 2013.

8. Ando K, Heymann MF, Stresing V, Mori K, Rédini F and Heymann D: Current therapeutic strategies and novel approaches in osteosarcoma. Cancers (Basel) 5: 591-616, 2013.

9. Pala E, Trovarelli G, Calabrò T, Angelini A, Abati CN and Ruggieri P: Survival of modern knee tumor megaprostheses: Failures, functional results, and a comparative statistical analysis. Clin Orthop Relat Res 473: 891-899, 2015.

10. Holzapfel BM, Pilge H, Prodinger PM, Toepfer A, Mayer-Wagner S, Hutmacher DW, von Eisenhart-Rothe R, Rudert M, Gradinger R and Rechl H: Customised osteotomy guides and endoprosthetic reconstruction for periacetabular tumours. Int Orthop 38: 1435-1442, 2014.

11. Wang W, Bi WZ, Yang J, Han G and Jia JP: Pelvic reconstruction with allogeneic bone graft after tumor resection. Acta Ortop Bras 21: 150-154, 2013.

12. Wang D, Ma D, Wong ML and Wáng YX: Recent advances in surgical planning \& navigation for tumor biopsy and resection. Quant Imaging Med Surg 5: 640-648, 2015.

13. Chou YC, Lee D, Chang TM, Hsu YH, Yu YH, Liu SJ and Ueng SW: Development of a three-dimensional (3D) printed biodegradable cage to convert morselized corticocancellous bone chips into a structured cortical bone graft. Int J Mol Sci 17: 595,2016

14. Nakamura T, Matsumine A, Uchida A, Kawai A, Nishida Y, Kunisada T, Araki N, Sugiura H, Tomita M, Yokouchi M, et al: Clinical outcomes of Kyocera modular limb salvage system after resection of bone sarcoma of the distal part of the femur: The Japanese Musculoskeletal Oncology Group Study. Int Orthop 38: 825-830, 2014

15. Zhang P, Feng F, Cai Q, Yao W, Gao S, Wang J and Wang X: Effects of metaphyseal bone tumor removal with preservation of the epiphysis and knee arthroplasty. Exp Ther Med 8: 567-572, 2014.

16. Bernthal NM, Greenberg M, Heberer K, Eckardt JJ and Fowler EG: What are the functional outcomes of endoprosthestic reconstructions after tumor resection? Clin Orthop Relat Res 473: 812-819, 2015 . 